\title{
Exposure and dose assessment to particle components among an elderly population
}

\author{
M. Almeida-Silva ${ }^{\text {a, b, }{ }^{*}, \text { S.M. Almeida }}{ }^{\text {a }}$, P.N. Pegas ${ }^{\text {c }}$, T. Nunes ${ }^{\text {c }}$, C.A. Alves ${ }^{\text {, }}$, \\ H.T. Wolterbeek ${ }^{\mathrm{b}}$ \\ a Centro de Ciências e Tecnologias Nucleares, Instituto Superior Técnico, Universidade de Lisboa, EN 10, km 139.7, 2695-066 Bobadela LRS, Portugal \\ ${ }^{\mathrm{b}}$ Faculty of Applied Sciences, Department of Radiation, Radionuclides and Reactors, Section RIH, Technical University of Delft, Delft, The Netherlands \\ c CESAM, Universidade de Aveiro, 3810-193 Aveiro, Portugal
}

\section{H I G H L I G H T S}

- Elderly spend 95\% of their time indoors.

- Indoor air quality was closely linked to personal exposure.

- The exposure and the inhaled dose of the studied elders differed significantly.

- The contribution of each indoor micro-environment depended on the particle constituents and respective sources.

\section{A R T I C L E I N F O}

\section{Article history:}

Received 9 June 2014

Received in revised form

26 November 2014

Accepted 27 November 2014

Available online 28 November 2014

\section{Keywords}

Elderly

Exposure

Dose

Particles

Carbonaceous components

Trace elements

\begin{abstract}
A B S T R A C T
People spend the majority of their time indoors and the composition and toxicity of indoor particles is very complex and present significant differences comparing with outdoor aerosols. Consequently, ambient particles cannot represent a real exposure. The aim of this work was to determine the daily exposure and the daily inhaled dose to particle components of elders living in Elderly Care Centers. A questionnaire was applied to 193 institutionalized elders in order to achieve their daily time pattern and to define the micro-environments where $\mathrm{PM}_{10}$ and its components (carbonaceous components and trace elements) were assessed. Daily exposure was calculated by integrating the elder's time spend in each micro-environment and the concentration of the pollutants for the period of interest. This parameter, together with the inhalation rate and the standard body weight, were used to calculate the daily inhaled dose. $\mathrm{PM}_{10}$ daily exposure and daily inhaled dose ranged between $11-16 \mu \mathrm{g} \mathrm{m}^{-3}$ and $20 \times 10^{-3}$ $28 \times 10^{-3} \mu \mathrm{g} \mathrm{kg}^{-1}$, respectively. This work not only allowed a fully quantification of the magnitude of the elders exposure, but also showed that the assessment of the integrated exposure to PM components is determinant to accomplish the dose inhaled by elders living in ECCs.
\end{abstract}

(C) 2014 Elsevier Ltd. All rights reserved.

\section{Introduction}

The concerning about exposure to particulate air pollution and their possible human health effects is not a current problem. In 1875 arose the first legal document containing a section called "nuisances" where it was required the decrease of smoke pollution in urban areas (Public Health Act, 1875). Meanwhile, several

\footnotetext{
* Corresponding author. Centro de Ciências e Tecnologias Nucleares, Instituto Superior Técnico, Universidade de Lisboa, EN 10, km 139.7, 2695-066 Bobadela LRS, Portugal.

E-mail address: marina@ctn.ist.utl.pt (M. Almeida-Silva).
}

epidemiological studies have established associations between exposure to Particulate Matter (PM) and adverse human health effects (Almeida et al., 2014a; Almeida-Silva et al., 2013; Pope et al., 2011, 2002). More recently, some researchers have investigated which properties of ambient aerosol are responsible for health effects; whether certain particulate chemical components are more harmful than others (Suh et al., 2011; Zanobetti et al., 2009); and the particle size as an important determinant of the site and efficiency of pulmonary deposition (Andersen et al., 2008).

However, epidemiological associations between PM and health outcomes are based predominantly on ambient air measurements where it is assumed that each person in a given region has the same exposure level, which is often obtained from a few air quality 
monitors and reflects the entire community (Almeida et al., 2009a: Freitas et al., 2009a,b; Sarmento et al., 2011). Nevertheless, poor correlations have been found between ambient PM concentrations and personal exposure to PM (Meng et al., 2005) because actual exposure is strongly related to the individual time activity patterns, followed by its distance from each particle source. Moreover, indoor environments has gain an increasing importance since in developed countries daily patterns had changed and people spend more than $80-90 \%$ of their time indoors (Zhao et al., 2009; Klepeis et al., 2001).

According to Morawska et al. (2013), up to 30\% of the burden of disease from PM exposure can be attributed to indoor-generated particles, signifying that indoor environments are likely to be a dominant factor affecting human health. This initiated a debate as to whether ambient PM is a good surrogate for exposure to PM once the composition and toxicity of indoor PM is very complex, with similarities but also differences to outdoor aerosols. Therefore, personal integrated exposure to PM components is of considerable importance as it is the key determinant of the PM dose received by an individual and thus directly influences the health impacts.

These facts are particularly relevant when we are talking about institutionalized elderly people not only because they are consider a susceptible group but also because they spend the majority of their time indoors (Almeida-Silva et al., 2014a; Saksena et al., 2003). Besides the increasing number of studies reporting pollutant concentrations in different micro-environments, the integrated exposure or integrated dose of the people was not successfully estimated. Moreover, as far as we know the assessment of the daily exposure to PM components (trace elements and carbonaceous components) and the estimation of the daily dose was never done, even for children which are the most studied population's group.

Therefore, a monitoring programme was designed to evaluate not only the Elderly Care Centers (ECCs) chemical and biological contamination but also the elderly daily exposure and inhaled dose to different air pollutants. The project followed the Risk Assessment

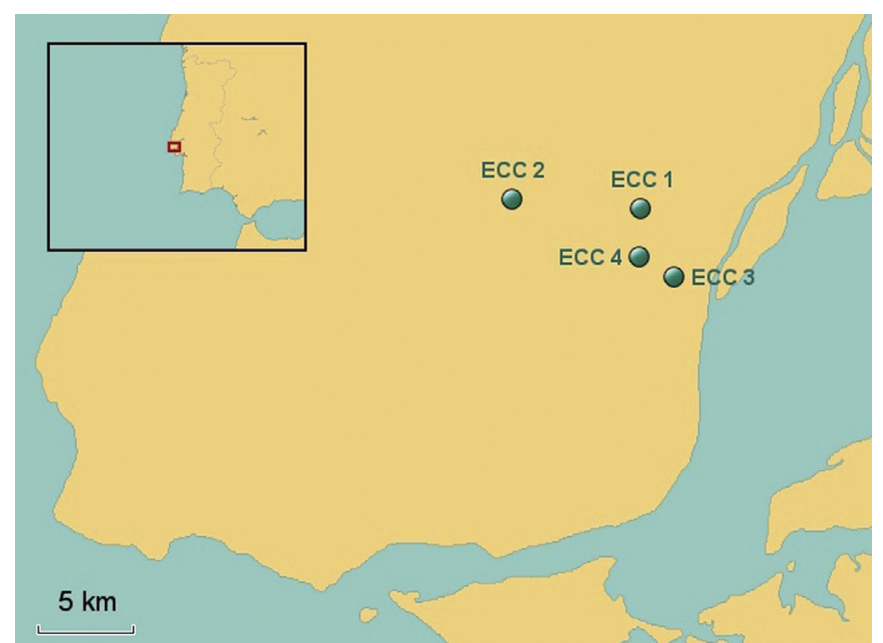

Fig. 2. Localization of the elderly Care centers.

Paradigm that includes: 1) the evaluation of emission sources; 2) the identification and quantification of hazards; 3 ) the exposure assessment; 4) the quantification of the dose; and 5) the study of effects on human health (Fig. 1). Sampling campaigns were undertaken in 10 ECCs considering 384 old people living on these sites. Several results generated within this project were already reported and focused: 1) on the fungi contamination of ECCs (Viegas et al., 2014), 2) on the daily elders exposure to carbon dioxide, carbon monoxide, PM in different sizes fractions, total volatile organic compounds, ozone and formaldehyde (Almeida-Silva et al., 2014a) and 3) on the nanoparticles deposition into elderly lungs (Almeida-Silva et al., 2014b). The objective of the present work was to characterize the $\mathrm{PM}_{10}$ components measured in the indoor air of ECCs, in order to assess the daily exposure and the inhaled dose of institutionalized elders to air pollutants.

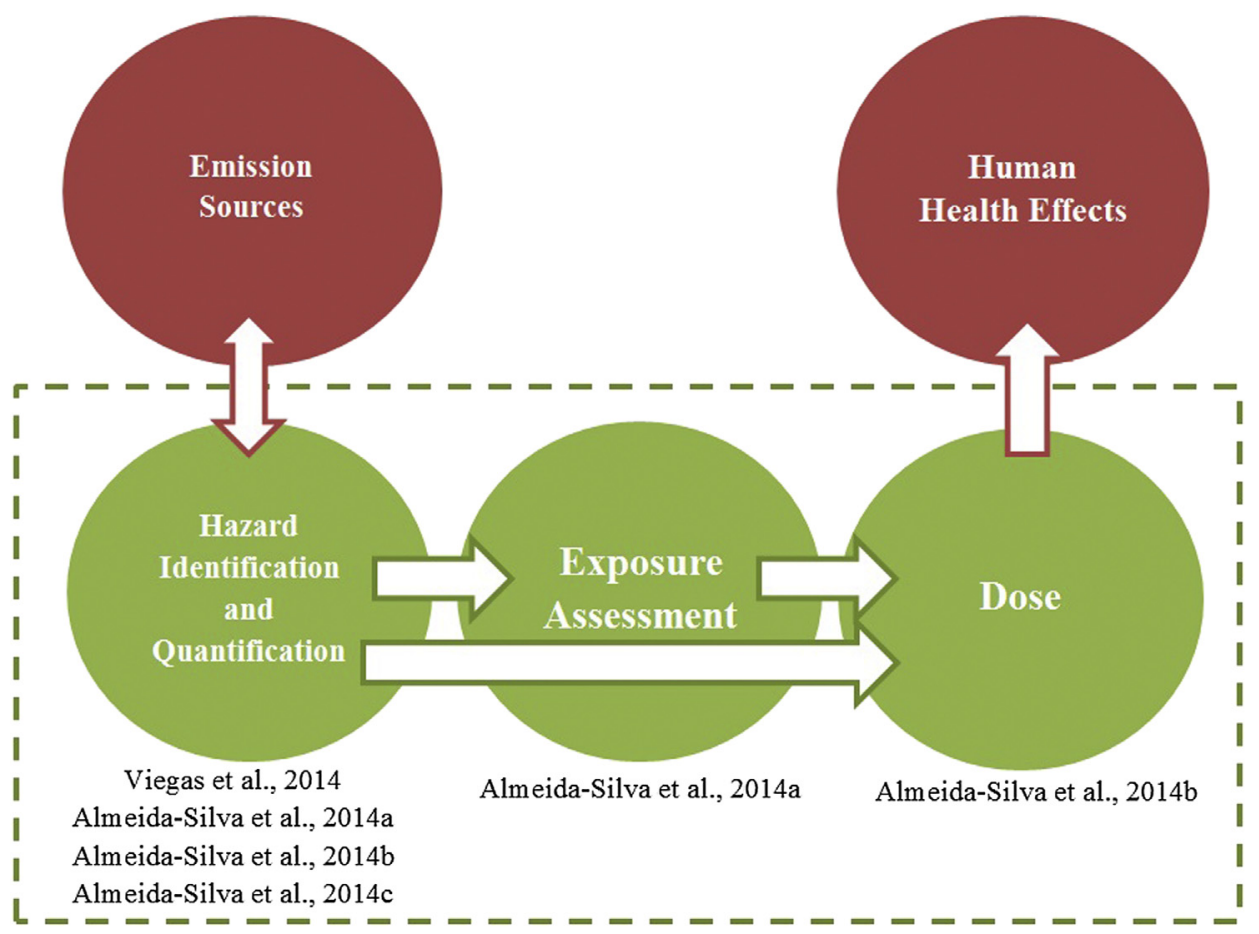

Fig. 1. Risk assessment paradigm applied in this work. 
Table 1

Characterization of the studied population. The results are presented in absolute values. (N/A means Not Applicable).

\begin{tabular}{|c|c|c|c|c|}
\hline & \multicolumn{2}{|c|}{ Women } & \multicolumn{2}{|c|}{ Men } \\
\hline & $N$ & Age (min-max) & $N$ & Age $(\min -\max )$ \\
\hline ECC 1 & 26 & $84(68-99)$ & 11 & $81(67-91)$ \\
\hline ECC 2 & 40 & 87 (74-99) & 11 & $88(76-96)$ \\
\hline ECC 3 & 39 & $88(77-100)$ & 0 & $\mathrm{~N} / \mathrm{A}$ \\
\hline ECC 4 & 42 & $84(70-99)$ & 24 & $82(70-90)$ \\
\hline Total & \multicolumn{2}{|c|}{147 ( 22 bedridden) } & \multicolumn{2}{|c|}{46 ( 6 bedridden) } \\
\hline
\end{tabular}

\section{Material and methods}

The current work was carried out in four Elderly Care Centers located in Loures that belongs to the metropolitan area of Lisbon, the capital city of Portugal (Fig. 2).

\subsection{Characterization of population}

The present work was developed in collaboration with 193 old people living in the selected ECCs, which had a range of 37-66 occupants per institution. Table 1 shows the characterization of the studied population. Women not only were presented in higher number, but also were older than men and were the ones who were bedridden in greater number.

\subsection{Characterization of ECCS}

Considering the particular characteristics of the surrounding environment, ECCs were classified as urban or sub-urban. A technical questionnaire was applied in order to characterize the buildings. This questionnaire included information about: ventilation systems, types of indoor materials, ventilation and cleaning practices, type of building construction, thermal isolation of the building and characterization of the building envelope. Table 2 summarizes buildings' characteristics. ECC 1, 2 and 3 were located in a sub-urban area whereas ECC 4 was in an urban area. Only ECC 1 had heating, ventilation and air-conditioning (HVAC) system, however its utilization was rare. The pavement of ECC 2 and 3 was covered by wood in both bedroom and living-room. The material of ECC 1 and ECC 4 bedrooms pavement was vinyl and the pavement material of living-rooms were made of epoxy and tile, respectively. For all ECCs the windows were made of aluminium with double glass. The cleaning maintenance frequency varied from 1 time a day and 1 time a week, being the living-rooms the indoor micro-environment with the highest frequency of cleanliness. This fact was due to the large number of elders that spend more than $8 \mathrm{~h}$ per day in this micro-environment.

\subsection{Time-budget survey}

Time-budget surveys (TBS) are useful tools to estimate the people exposure to air pollutants, due to the fact that they give us the time spent by people in different locations.
A close-ended questionnaire was designed, which included information about different activities developed during the day, mealtimes, sleep times, micro-environments where elders spend their time, etc. The questionnaire differentiated between time allocation on weekdays and weekends. The questionnaires were applied with the help of the ECCs supporters (e.g. socio-cultural technicians) and due to this fact the response rate was $100 \%$ for all studied sites.

Considering the time-budget data, an elderly daily pattern was achieved in order to identify the most occupied microenvironments. All the results were pondered to $24 \mathrm{~h}$.

\section{4. $P M_{10}$ sampling}

PM with an aerodynamic diameter lower than $10 \mu \mathrm{m}\left(\mathrm{PM}_{10}\right)$ was sampled in four ECCs during the occupied periods in two different indoor micro-environments: bedrooms during the night and livingrooms during the day. The bedrooms were chosen according to the occupancy - two persons per bedroom. All the selected bedrooms were occupied by two elders to keep the occupancy as a constant and because this occupancy reflects the reality of the majority of the bedrooms in the studied ECCs. As the physical characteristics of all bedrooms in each ECC were equivalent it was decided to select only one bedroom per ECC. ECC 3 and ECC 4 had one living-room whereas ECC 1 and ECC 2 had two living-rooms with the same characteristics, and therefore only one of living-room was selected.

The sampling campaign occurred between October and November of 2012, avoiding extreme temperature and humidity.

In the indoor of each ECC, PM $_{10}$ was collected with two TCRTecora ${ }^{\circledR}$ samplers operating at a flow rate of $2.3 \mathrm{~m}^{3} \mathrm{~h}^{-1}$ (in accordance with the EN 12341), equipped with a $\mathrm{PM}_{10}$ EN sampling head). One sampler collected particles onto quartz filters and another onto teflon filters, both with a diameter of $47 \mathrm{~mm}$. The sampling time ranged from 10 to $16 \mathrm{~h}$, during the occupancy period for each selected micro-environment: bedroom and living-room. Outdoor measurements were performed in parallel with two different samplers: 1) a Partisol ${ }^{\mathrm{TM}}$ Plus 2025 Sequential Ambient Particulate Sampler, operating at a flow rate of $1.0 \mathrm{~m}^{3} \mathrm{~h}^{-1}$ and collecting particles onto teflon filters and 2) a Leckel Medium Volume Sampler 6, operating at a flow rate of $3.5 \mathrm{~m}^{3} \mathrm{~h}^{-1}$ and collecting particles onto quartz filters.

Carbonaceous components were determined in $\mathrm{PM}_{10}$ deposited onto quartz filters whereas teflon filters were used to measure the elemental composition of aerosols.

\subsection{Determination of the $P M_{10}$ mass concentration}

The collected filters were weighted using a Mettler ${ }^{\circledR}$ Toledo balance with $0.1 \mu \mathrm{g}$ readability. The balance was placed in a controlled clean room (class 10,000) at a temperature of $20 \pm 1{ }^{\circ} \mathrm{C}$ and a relative humidity of $50 \pm 5 \%$. Before being weighted filters were equilibrated for $24 \mathrm{~h}$ in the same room. Filters were weighted before and after sampling and the mass of particulate matter was

Table 2

Characterization of the Elderly Care Centers. (BR and LR mean Bedroom and Living-room, respectively).

\begin{tabular}{|c|c|c|c|c|c|c|c|c|c|c|}
\hline \multirow[t]{2}{*}{ ECC } & \multirow[t]{2}{*}{ Season of sampling } & \multirow[t]{2}{*}{ Zone } & \multirow[t]{2}{*}{ Type of building } & \multirow[t]{2}{*}{ N..$^{\circ}$ of Beds } & \multirow[t]{2}{*}{ HVAC } & \multicolumn{2}{|c|}{ Pavement } & Windows & \multicolumn{2}{|c|}{ Cleaning frequency } \\
\hline & & & & & & $\mathrm{BR}$ & LR & BR & $\mathrm{BR}$ & LR \\
\hline ECC 1 & Autumn & Sub-urban & Villa (with 3 floors) & 37 & Yes & Vinyl & Epoxy & Double glass aluminium & $1 \times$ day & $1 \times$ day \\
\hline ECC 2 & Autumn & Sub-urban & Villa (with 3 floors) & 51 & No & Wood & & Double glass aluminium & $1 \times$ week & $1 \times$ day \\
\hline ECC 3 & Autumn & Sub-urban & Villa (with 2 floors) & 40 & No & Wood & & Double glass aluminium & $1 \times$ day & $1 \times$ day \\
\hline ECC 4 & Autumn & Urban & Villa (with 3 floors) & 69 & No & Vinyl & Tile & Double glass aluminium & $1 \times$ day & $1 \times$ day \\
\hline
\end{tabular}


obtained as the average of three measurements, when the observed variations were less than $5 \mu \mathrm{g}$.

\subsection{Analysis of carbonaceous components}

The elemental and organic carbon (EC and OC) content in $\mathrm{PM}_{10}$ was analysed in Aveiro University by a home-made thermal-optical transmission system, after a passive exposure of the sampled filters to vapours of hydrochloric acid $(\mathrm{HCl}-6 \mathrm{M})$ for approximately $4 \mathrm{~h}$ to remove carbonate interferences. After this period, samples were kept overnight in a desiccator with hydroxide sodium $(\mathrm{NaOH})$ to neutralize any excess of acid in samples. This procedure was at first developed by Carvalho et al. (2006) and recently adapted by Alves et al. (2011). Controlled heating in anoxic and oxic conditions was performed to separate, respectively, OC into two fractions of increasing volatility and EC, which were then measured in the form of $\mathrm{CO}_{2}$ by an infrared non-dispersive analyser. The first fraction corresponded to the volatilization at $\mathrm{T}<200{ }^{\circ} \mathrm{C}$ of lower molecular weight organics. The second fraction was related to the decomposition and oxidation of higher molecular weight species at temperatures ranging from 200 to $600{ }^{\circ} \mathrm{C}$. However, pyrolysed organic carbon (PC), formed during the previous heating steps, was only released in oxic conditions, when the sample was heated up to $850^{\circ} \mathrm{C}$, evolving simultaneously with EC. The interference between PC and EC was controlled by continuous evaluation of the blackening of the filter using a laser beam and a photodetector that measured the light transmittance. The split between the PC and EC was assigned when the initial (baseline) value of the filter transmittance was reached. All carbon removed before the split was considered organic, and that removed after the split was considered elemental.

Carbonates $\left(\mathrm{CO}_{3}^{2-}\right)$ in $\mathrm{PM}_{10}$ samples were analysed through the release of $\mathrm{CO}_{2}$, and measured by the same non-dispersive infrared analyser coupled to the thermo-optical system, when a punch of each filter was acidified with orthophosphoric acid (20\%) in a free $\mathrm{CO}_{2}$ gas stream (Alves et al., 2011).

Three blank quartz filters were treated at the same conditions as samples. The concentrations were corrected according to blanks results by subtracting those values.

\subsection{Analysis of trace elements}

Trace elements in filters were measured by $k_{0}$-Instrumental Neutron Activation Analysis ( $k_{0}$-INAA) in IST (Almeida et al., 2013a). One half of the filter was rolled up, put into an aluminium foil and irradiated at the Portuguese Research Reactor (nominal power: $1 \mathrm{MW}$ ) during $5 \mathrm{~h}$. After the irradiation, filters were removed from the aluminium foil and were inserted in polyethylene containers. Samples were measured during 7-10 h after 2-5 days and 4 weeks of decay, in a coaxial germanium detector, associated to an ORTEC ${ }^{\circledR}$ Automatic Sample Changer. A comparator - Al-0.1\% Au alloy disk with a thickness of $125 \mu \mathrm{m}$ and a diameter of $0.5 \mathrm{~cm}$ - was coirradiated with the samples for the application of the $k_{0}$-INAA methodology (De Corte, 1987).

Three blank teflon filters were treated at the same conditions as samples. The elemental concentrations were corrected according to blank results by subtracting those values.

Quality control was pursued by the use of the NIST-SRM ${ }^{\circledR} 1633 \mathrm{a}-$ Coal Fly Ash certified reference material (Dung et al., 2010; Almeida et al., 2014b). Approximately $130 \mathrm{mg}$ of reference material was coirradiated with each batch of samples and measured for $60 \mathrm{~min}$ after 2-5 days and 4 weeks of decay using the same detector. A good agreement was obtained, with deviations from reference values below $20 \%$, with $95 \%$ of confidence level (Almeida-Silva et al., 2014c).

\subsection{Statistics}

Statistical analysis of all data was performed using the STATISTICA $^{\circledR}$ software. The Mann-Whitney U-test and Wilcoxon Matched pairs were applied to detect statistically significant differences between each indoor micro-environment (independent samples) and between indoor and outdoor results (dependent samples), respectively. The criterion for significance was set at $p<0.05$.

\section{Results and discussion}

\subsection{Hazard identification and quantification}

\subsection{1. $P M_{10}$ concentration}

Considering the fact that elders living in ECCs spend most of their time in bedrooms and living-rooms, $\mathrm{PM}_{10}$ was evaluated for these two indoor micro-environments. Fig. 3 summarizes the indoor and respective outdoor $\mathrm{PM}_{10}$ concentrations measured in the 4 studied ECCs. The average $\mathrm{PM}_{10}$ concentration in bedroom and living-room was $11 \mu \mathrm{g} \mathrm{m}^{-3}$ and $19 \mu \mathrm{g} \mathrm{m}^{-3}$, respectively. Livingrooms presented significant higher $\mathrm{PM}_{10}$ concentrations when compared with bedrooms $(p=0.006$ ) because living-rooms had more occupants. Several studies have already showed a relation between high levels of occupancy and high $\mathrm{PM}_{10}$ concentrations due to the effect of the re-suspension of dust (Canha et al., 2014b). $\mathrm{PM}_{10}$ concentrations in bedroom were significantly lower comparing with the correspondent outdoor $(p=0.005)$ whereas no significantly differences were observed between living-rooms and the outdoor $(p=0.590)$. These results are probably explained by the fact that during the occupancy period bedrooms had the windows closed while in living-rooms the doors and windows were open promoting a bigger circulation of air from the outdoor. $\mathrm{PM}_{10}$ indoor concentrations did not exceed the reference value of $50 \mu \mathrm{g} \mathrm{m}^{-3}$ established by the Portuguese legislation for indoor air quality and by the World Health Organization (2010).

A study developed in UK residences presented similar results with $\mathrm{PM}_{10}$ average concentrations measured in living-rooms ranging between $13 \mu \mathrm{g} \mathrm{m}^{-3}$ and $22 \mu \mathrm{g} \mathrm{m}^{-3}$ (Nasir and Colbeck, 2013). However, comparing the current results with the majority of studies developed in different public indoor micro-environments it is possible to observe that $\mathrm{PM}_{10}$ concentration evaluated inside these ECCs were lower. Indeed, in these indoor microenvironments the movement of people is limited since most of the institutionalized elders are semi-autonomous. Consequently,

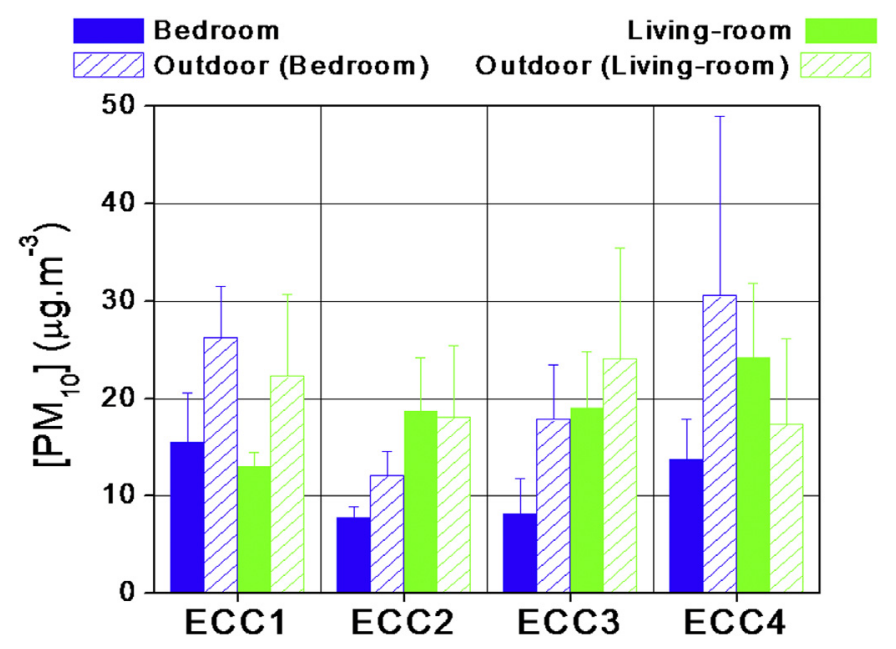

Fig. 3. $\mathrm{PM}_{10}$ concentration in ECCs' micro-environments. 
the possibility of re-suspension of dust is lower comparing with other crowded indoor environments such as hospitals, schools and offices (Slexakova et al., 2012; Canha et al., 2012b). For instance, a study developed in a Portuguese hospital showed $\mathrm{PM}_{10}$ variations between $13 \mu \mathrm{g} \mathrm{m}^{-3}$ and $59 \mu \mathrm{g} \mathrm{m} \mathrm{m}^{-3}$ (Slexakova et al., 2012). Zwozdziak et al. (2013) studied the indoor air quality in schools from Poland and showed a range of $\mathrm{PM}_{10}$ concentrations between $43 \mu \mathrm{g} \mathrm{m}^{-3}$ and $69 \mu \mathrm{g} \mathrm{m}^{-3}$. Another study performed in Portuguese schools presented much higher $\mathrm{PM}_{10}$ concentrations, which varied between $30 \mu \mathrm{g} \mathrm{m}^{-3}$ and $146 \mu \mathrm{g} \mathrm{m}^{-3}$ (Almeida et al., 2011). In offices, several works also presented higher $\mathrm{PM}_{10}$ concentrations than in the current study, with a variation from $10 \mu \mathrm{g} \mathrm{m}^{-3}$ to $480 \mu \mathrm{g} \mathrm{m}^{-3}$ (Han et al., 2011; Valuntaité et al., 2008; Reynolds et al., 2001).

Besides the low concentrations measured in this study it is wellknown that $\mathrm{PM}_{10}$ enhances adverse health effects and it is unclear whether a threshold concentration exists for PM below which no effects on health are likely. Moreover, in this study elderly population is considered which not only is more susceptible to air pollutants but also live and spend most of their time in these microenvironments.

\subsection{2. $P M_{10}$ components}

Table 3 summarizes the average and the standard deviation of the $\mathrm{PM}_{10}$ components. On average, the sum of the indoor $\mathrm{PM}_{10}$ components (OC, $\mathrm{EC}, \mathrm{CO}_{3}^{2-}$ and trace elements) measured in this work corresponded to $51 \%$ of the total $\mathrm{PM}_{10}$ mass measured by gravimetry.

The major component measured in $\mathrm{PM}_{10}$ was the carbonaceous fraction (OC, $\mathrm{EC}$ and $\mathrm{CO}_{3}^{2-}$ ), representing in average $47 \%$ of the total indoor $\mathrm{PM}_{10}$ mass measured by gravimetry. Results showed that the concentration of these compounds were significantly higher indoors $(p<0.05)$. On average, OC accounted for $28 \%$ of the mass of $\mathrm{PM}_{10}$ indoors, whereas a lower mass fraction was found outdoors (10\%), which represented an I/O ratio of 2.7 . The I/O ratio for EC and $\mathrm{CO}_{3}^{2-}$ presented lower values due to the influence of traffic and dust re-suspension at roadside, respectively.

The lack of correlation between indoor and outdoor EC and, principally OC, could be due to significant contributions of indoor sources. Cleary, OC was enriched in indoor as compared to outdoor. Among the indoor sources of organic compounds, sub-micrometer fragments of paper, skin debris, clothing fibres, cleaning products and waxes may be considered (Alves et al., 2014).

\section{Table 3}

Summary of $\mathrm{PM}_{10}$ concentration and $\mathrm{PM}_{10}$ components measured in bedrooms and living-rooms, and the respective outdoors.

\begin{tabular}{lcccc}
\hline & Bedroom & $\begin{array}{l}\text { Outdoor } \\
\text { bedroom })\end{array}$ & Living-room & $\begin{array}{l}\text { Outdoor } \\
\text { (living-room) }\end{array}$ \\
\hline $\mathrm{PM}_{10}\left(\mu \mathrm{g} \mathrm{m}^{-3}\right)$ & $10.9 \pm 4.4$ & $23.5 \pm 11.7$ & $18.5 \pm 6.3$ & $20.7 \pm 8.2$ \\
Carbonaceous components $\left(\mu \mathbf{g ~ m}^{-\mathbf{3}}\right)$ & & & \\
$\mathrm{OC}$ & $3.0 \pm 1.2$ & $2.2 \pm 0.9$ & $4.3 \pm 1.5$ & $1.7 \pm 0.8$ \\
$\mathrm{EC}$ & $0.69 \pm 0.45$ & $0.67 \pm 0.42$ & $1.45 \pm 0.66$ & $1.21 \pm 0.97$ \\
$\mathrm{CO}_{3}^{2-}$ & $1.3 \pm 0.48$ & $1.5 \pm 1.5$ & $2.0 \pm 1.0$ & $1.6 \pm 1.2$ \\
Elements $\left(\mathbf{n g ~ m}^{-3}\right)$ & & & \\
$\mathrm{As}$ & $0.28 \pm 0.36$ & $0.88 \pm 1.5$ & $0.33 \pm 0.22$ & $0.94 \pm 0.65$ \\
$\mathrm{Ce}$ & $0.47 \pm 0.37$ & $0.35 \pm 0.1$ & $0.37 \pm 0.14$ & $0.42 \pm 0.07$ \\
$\mathrm{Co}$ & $0.06 \pm 0.05$ & $0.19 \pm 0.15$ & $0.11 \pm 0.06$ & $0.21 \pm 0.07$ \\
$\mathrm{Cr}$ & $9.2 \pm 4.4$ & $9.1 \pm 5.3$ & $11.9 \pm 2.3$ & $14.2 \pm 5.8$ \\
$\mathrm{Fe}$ & $48 \pm 29$ & $270 \pm 220$ & $225 \pm 187$ & $450 \pm 390$ \\
$\mathrm{~K}$ & $100 \pm 52$ & $960 \pm 1460$ & $160 \pm 78$ & $800 \pm 960$ \\
$\mathrm{Na}$ & $201 \pm 171$ & $920 \pm 460$ & $435 \pm 121$ & $1850 \pm 1630$ \\
$\mathrm{Sb}$ & $0.49 \pm 0.34$ & $1.9 \pm 1.3$ & $1.4 \pm 1.2$ & $2.2 \pm 1.9$ \\
$\mathrm{Sc}$ & $0.004 \pm 0.003$ & $0.03 \pm 0.01$ & $0.02 \pm 0.02$ & $0.03 \pm 0.03$ \\
$\mathrm{Sm}$ & $0.003 \pm 0.001$ & $0.017 \pm 0.01$ & $0.01 \pm 0.01$ & $0.05 \pm 0.05$ \\
$\mathrm{Zn}$ & $26 \pm 14$ & $27 \pm 23$ & $39 \pm 16$ & $32 \pm 19$ \\
\hline
\end{tabular}

Organic to elemental carbon (OC/EC) ratios exceeding 2.0 have been used to identify the presence of secondary organic aerosols (SOA) (Chow et al., 1996) in urban areas where traffic emissions have a significant contribution to the EC levels. In this study, the average indoor OC/EC ratio was 5.4, which denotes a significant increase in $\mathrm{OC}$ levels that could be not only to primary indoor sources but as well to SOA production. The formation of SOA in indoor environments was demonstrated and confirmed in test chambers experiments, done by Aoki and Tanabe (2007). Sportion of semi-volatile organic compounds could be as well as important indoor source of organic matter. Thus, the combination of active indoor sources, sorptive processes and SOA formation leaded to an enrichment of the indoor particles in OC and to high OC/EC ratios inside the ECCs (Alves et al., 2014). Besides the lowest concentrations of OC and EC measured in bedrooms, the ratio OC/EC was higher in bedrooms (7.7) than in living-rooms (3.3), not only due to the higher contribution of skin debris, clothing fibres and cleaning products in bedrooms, which have a smaller area, but also due to less exchange with outdoor air with lower OC/EC ratios, increasing the probability of SOA formation.

Fig. 4 shows an opposite behaviour for the trace elements measured in $\mathrm{PM}_{10}$. Only $\mathrm{Zn}$ and $\mathrm{Cr}$ in some ECCs presented $\mathrm{I} / \mathrm{O}$ ratios higher than 1, indicating the existence of indoor sources for these elements, although these elements are normally associated with traffic and industrial emissions (Zechmeister et al., 2005). Actually, other studies, which have also observed significantly higher concentration of $\mathrm{Zn}$ and $\mathrm{Cr}$ indoors (Chithra and Nagendra, 2013), suggested that $\mathrm{Zn}$ provides from several products which are applied indoors to protect steel, walls, wood surfaces, doors and windows (Avigo et al., 2008) and $\mathrm{Cr}$ can be derived from burning coal and kerosene (Joshi et al., 2010). The elements that presented higher concentration outdoors are essentially associated with outdoor anthropogenic sources related to traffic and industry (As, K and $\mathrm{Sb}$ ) (Almeida et al., 2009a,b), dust re-suspension (Ce, Co, Fe, K, Sc and Sm) (Almeida-Silva et al., 2011; Almeida et al., 2008), biomass burning (K) (Canha et al., 2012c) and sea spray (Na) (Almeida et al., 2013b). The higher or less decrease of $\mathrm{I} / \mathrm{O}$ ratios observed among the different elements can also find an explanation in the size distribution associated with each element. Coarse particles fall down faster than fine particles, decreasing the particles population in the highest sizes. Elements with the lowest $\mathrm{I} / \mathrm{O}$ ratios probably are associated to the coarse aerosol fraction $(2.5-10 \mu \mathrm{m})$, whereas an $\mathrm{I} / \mathrm{O}$ ratio close to one can be mainly associated to fine particles $(d p<2.5 \mu \mathrm{m})$.

All the measured $\mathrm{PM}_{10}$ components presented significantly higher levels in living-rooms than in bedrooms, except Ce that did not present significant differences between both microenvironments. Living-rooms had more occupancy and indoor concentrations of dust particles were strongly influenced by activities and movement of occupants, which may allow the resuspension of previously deposited particles or their delayed deposition or settling. Moreover, the infiltration of outdoor air without any filtration was higher in living-rooms, increasing the contribution of outdoor sources into this micro-environment (Almeida-Silva et al., 2014a).

\subsection{Exposure assessment}

\subsubsection{Elderly daily pattern}

Several studies have already evaluated the daily time pattern of people from different countries (Fisher and Robinson, 2011; Eurostat, 2006, 2003). However, these studies either excluded the old people or studied simultaneously all age groups, from young children to elderly. 


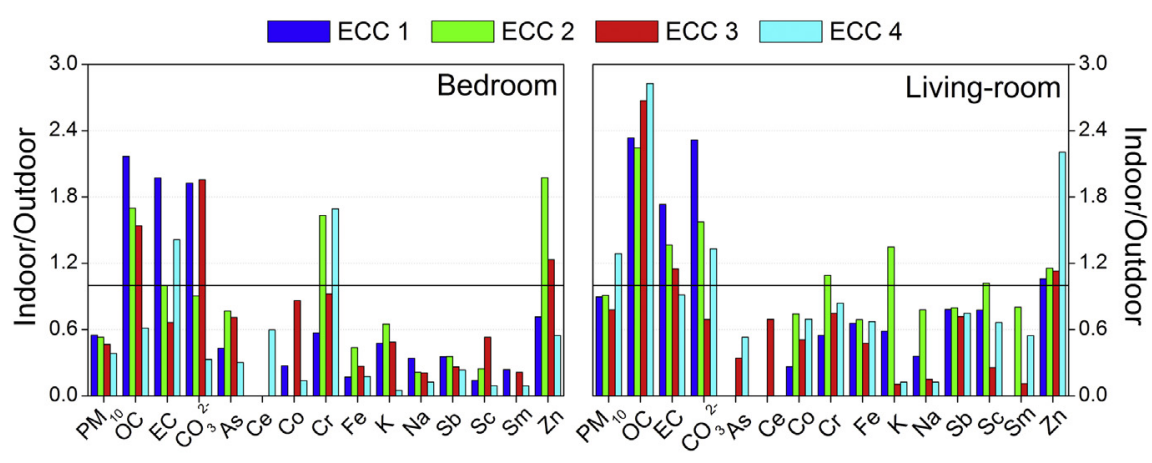

Fig. 4. Ratio indoor/outdoor for $\mathrm{PM}_{10}$ and its components.

Due to the scarcity of works focussing on time occupancy of elders living in ECCs, a questionnaire was applied to build a timebudget survey for the studied population and the following conclusions were achieved (Fig. 5): 1) the majority of the elders spent their time mainly in bedrooms and living-rooms; 2) a small percentage of old people went outside to stay in the ECC' garden or to go to another indoor places as family houses, restaurants or coffees and 3) $15 \%$ of the elders ( 22 women and 6 men) were bedridden and, therefore, they were always inside their bedrooms. Due to the lack of differences between weekdays and weekends, the results are presented for typical $24 \mathrm{~h}$.

In all ECC the same pattern was observed: from 8:00 to 20:00 the majority of the elders were in the living-rooms, moving to the canteen at the meal times and to the bedrooms at 21:00. In the specific case of ECC 4 there were elders who sometimes went to sleep in relative's house. It was also possible to observe that in ECC 3 and ECC 4 elders spent more time in living-room, since they only went to the canteen three times a day. In average, elders spent $15.2 \mathrm{~h}(63 \%)$ and $4.7 \mathrm{~h} \mathrm{(20 \% )}$ in bedroom and living-room, respectively (Table 4).

A study developed in Italy showed that elderly spent $70-83 \%$ of their time inside buildings (Simone et al., 2003), while The National Human Activity Pattern Survey (NHAPS) refers that the American elders spent $87 \%$ of their time indoors (Klepeis et al., 2001). The above mentioned works presented values lower than the ones obtained in this work, which could be explained by the fact that the present study only considers elders living in ECCs.

The authors created the micro-environment "others", which corresponds to other indoor micro-environments rather than the living-room or bedroom. For the calculation of exposure and dose, equivalent characteristics as the living-rooms were used for this micro-environment.

\subsubsection{Daily average exposure}

Daily average exposure for each elder $\left(E_{\mathrm{i}}\right)$ was assessed by integrating the results obtained from the time-budget survey with the pollutants concentrations measured in the different microenvironments. Hence, the Equation (1) was applied:

$E_{i}=\frac{\sum_{j=1}^{m} C_{i j} \cdot t_{i j}}{\sum_{j=1}^{m} t_{i j}}$

Where $C_{i j}$ is the concentration of the pollutant measured in the jth micro-environment of the ith individual, $t_{i j}$ is the time spent by the ith individual in the jth micro-environment. The total number of micro-environments is $m$ such that:

$\sum_{j=1}^{m} t_{i j}=24 \mathrm{~h}$

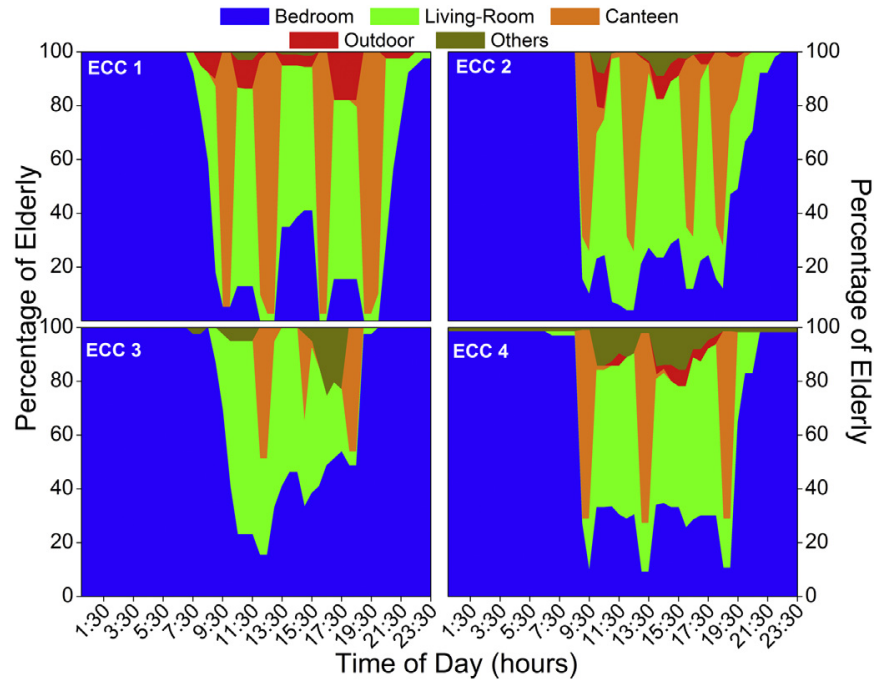

Fig. 5. Elderly daily pattern pondered to $24 \mathrm{~h}$.

Table 4

Time-Budget Survey data. Results are presented in hours.

\begin{tabular}{lllllll}
\hline & Bedroom & Living-room & Canteen & Outdoor & Others & Total \\
\hline ECC 1 & 12.5 & 5.2 & 4.6 & 0.8 & 1.0 & 24.0 \\
ECC 2 & 14.8 & 5.3 & 3.2 & 0.4 & 0.3 & 24.0 \\
ECC 3 & 18.3 & 3.6 & 1.3 & 0.0 & 0.8 & 24.0 \\
ECC 4 & 15.2 & 4.7 & 2.1 & 0.2 & 1.8 & 24.0 \\
\hline
\end{tabular}

Table 5 and Fig. 6 present the absolute and the relative, respectively, daily average exposure to air pollutants assessed in the four selected ECCs, considering $\mathrm{PM}_{10}$ and its components.

Individual $\mathrm{PM}_{10}$ daily average exposure varied between $11 \mu \mathrm{g} \mathrm{m}^{-3}$ in ECC 3 and $16 \mu \mathrm{g} \mathrm{m}^{-3}$ in ECC 4, which is located in an urban area. Although, the highest $\mathrm{PM}_{10}$ concentrations were registered inside living-rooms, the bedroom was the microenvironment that most contributed to the $\mathrm{PM}_{10}$ exposure (with an average of 52\%), being the ECC 4 bedroom the microenvironment that presented the highest level.

Higher daily exposure levels were registered in ECC 4 for the elements As, Fe, K, Sb, Sc and Sm (0.59, 150, 190, 0.97, 0.015 and $0.012 \mathrm{ng} \mathrm{m}^{-3}$, respectively). These elements presented $\mathrm{I} / \mathrm{O}$ ratios lower than one indicating their association with outdoor sources. This ECC is more affected by traffic, as it is located in an urban area, is near to a highway and is also less than $1 \mathrm{~km}$ from the Lisbon Airport. For the above mentioned elements, the contribution of the 
Table 5

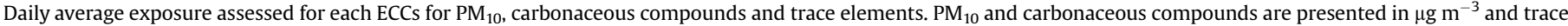
elements are presented in $\mathrm{ng} \mathrm{m}^{-3}$.

\begin{tabular}{|c|c|c|c|c|c|c|c|c|c|c|c|c|c|c|c|}
\hline & & $\mathrm{PM}_{10}$ & OC & $\mathrm{EC}$ & $\mathrm{CO}_{3}^{2-}$ & As & Co & $\mathrm{Cr}$ & $\mathrm{Fe}$ & K & $\mathrm{Na}$ & $\mathrm{Sb}$ & Sc & $\mathrm{Sm}$ & $\mathrm{Zn}$ \\
\hline \multirow[t]{5}{*}{ ECC 1} & $\mathrm{BR}$ & 7.8 & 2.6 & 0.44 & 0.91 & 0.068 & 0.023 & 3.6 & 20 & 52 & 135.4 & 0.23 & 0.002 & 0.002 & 6.6 \\
\hline & LR & 2.8 & 0.6 & 0.17 & 0.26 & 0.053 & 0.011 & 3.0 & 14 & 16 & 124.2 & 0.07 & 0.001 & 0.001 & 7.7 \\
\hline & Out & 0.71 & 0.06 & 0.02 & 0.02 & 0.005 & 0.006 & 0.71 & 6 & 6 & 42.2 & 0.03 & 0.001 & 0.001 & 0.97 \\
\hline & Others & 2.5 & 0.56 & 0.16 & 0.23 & 0.038 & 0.010 & 2.7 & 12 & 14 & 110.8 & 0.06 & 0.001 & 0.001 & 6.9 \\
\hline & Total & 14 & 3.9 & 0.78 & 1.4 & 0.16 & 0.050 & 10 & 50 & 88 & 413 & 0.39 & 0.005 & 0.005 & 22 \\
\hline \multirow[t]{5}{*}{ ECC 2} & BR & 4.9 & 1.7 & 0.42 & 0.98 & 0.055 & 0.00 & 2.7 & 16 & 44 & 123.6 & 0.23 & 0.001 & 0.000 & 7.1 \\
\hline & LR & 3.8 & 0.83 & 0.33 & 0.33 & 0.058 & 0.03 & 3.2 & 55 & 44 & 69.2 & 0.31 & 0.005 & 0.003 & 10.4 \\
\hline & Out & 0.26 & 0.03 & 0.01 & 0.02 & 0.002 & 0.001 & 0.11 & 3 & 1.9 & 11.6 & 0.02 & 0.000 & 0.000 & 0.32 \\
\hline & Others & 2.6 & 0.58 & 0.23 & 0.23 & 0.041 & 0.021 & 2.2 & 40 & 31 & 48.6 & 0.22 & 0.003 & 0.002 & 7.3 \\
\hline & Total & 12 & 3.1 & 1.0 & 1.6 & 0.16 & 0.052 & 8 & 110 & 121 & 253 & 0.78 & 0.009 & 0.005 & 25 \\
\hline \multirow[t]{5}{*}{ ECC 3} & $\mathrm{BR}$ & 6.8 & 2.6 & 0.49 & 0.87 & 0.089 & 0.060 & 5.1 & 30 & 47 & 81.4 & 0.25 & 0.004 & 0.002 & 26 \\
\hline & LR & 3.3 & 0.79 & 0.34 & 0.29 & 0.054 & 0.021 & 1.9 & 60 & 27 & 57.2 & 0.47 & 0.002 & 0.001 & 7.5 \\
\hline & Out & 0.0 & 0.0 & 0.00 & 0.00 & 0.00 & 0.00 & 0.00 & 0.00 & 0.00 & 0.00 & 0.00 & 0.000 & 0.000 & 0.0 \\
\hline & Others & 1.3 & 0.32 & 0.14 & 0.12 & 0.022 & 0.009 & 0.80 & 25 & 11 & 23.2 & 0.19 & 0.001 & 0.001 & 3.1 \\
\hline & Total & 11 & 3.7 & 0.97 & 1.3 & 0.17 & 0.090 & 78 & 115 & 85 & 162 & 0.90 & 0.007 & 0.004 & 37 \\
\hline \multirow[t]{5}{*}{ ECC 4} & BR & 7.9 & 1.1 & 0.44 & 0.49 & 0.39 & 0.038 & 10.1 & 50 & 97 & 107.9 & 0.51 & 0.003 & 0.002 & 25 \\
\hline & LR & 4.8 & 1.1 & 0.29 & 0.58 & 0.12 & 0.029 & 2.6 & 56.0 & 40 & 100.5 & 0.26 & 0.007 & 0.006 & 7.7 \\
\hline & Out & 0.22 & 0.021 & 0.009 & 0.019 & 0.014 & 0.002 & 0.10 & 3.7 & 20 & 22.5 & 0.02 & 0.000 & 0.000 & 0.4 \\
\hline & Others & 3.2 & 0.77 & 0.19 & 0.39 & 0.078 & 0.019 & 1.7 & 37.5 & 30 & 67.4 & 0.18 & 0.005 & 0.004 & 5.2 \\
\hline & Total & 16 & 3.03 & 0.94 & 1.5 & 0.59 & 0.088 & 15 & 150 & 190 & 298 & 0.97 & 0.015 & 0.012 & 38 \\
\hline$E_{\mathrm{i}}$ & & 13 & 3.4 & 0.92 & 1.4 & 0.27 & 0.07 & 10 & 110 & 121 & 380 & 0.76 & 0.009 & 0.006 & 31 \\
\hline
\end{tabular}

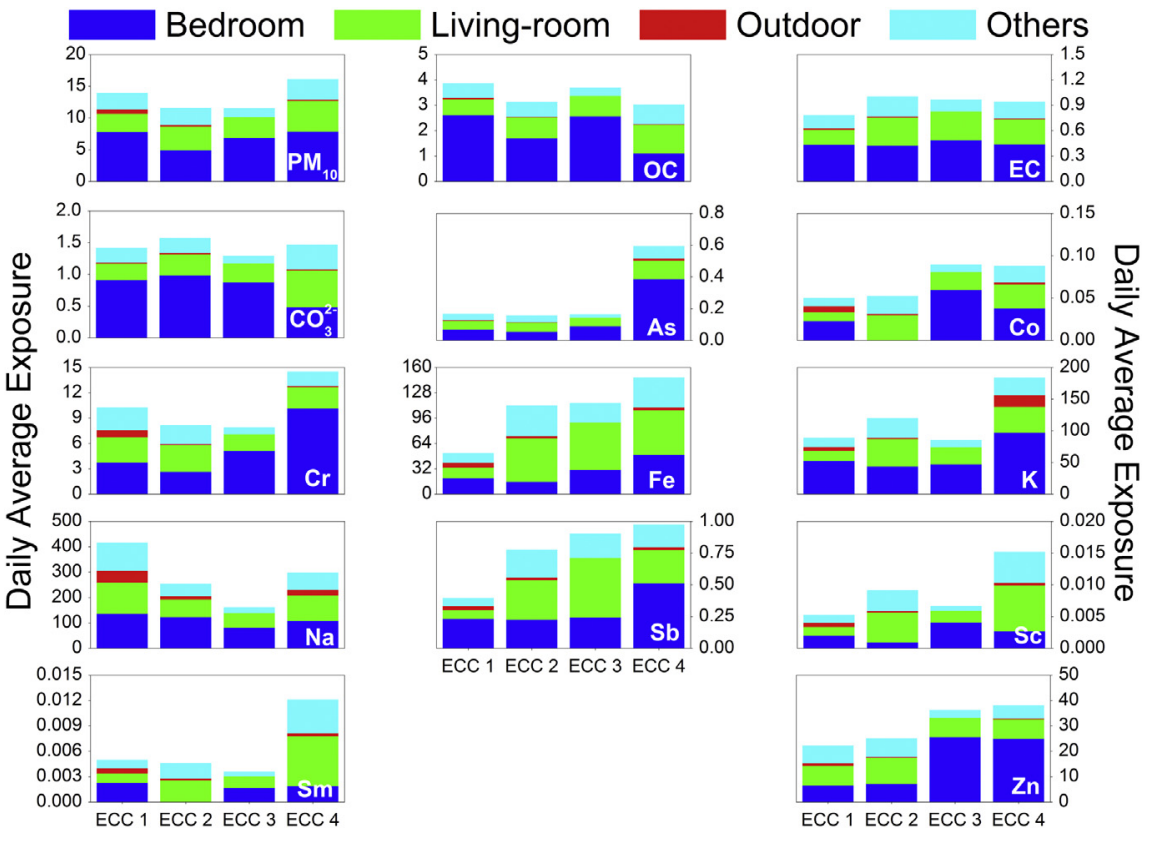

Fig. 6. Contribution of micro-environments to elderly daily exposure (values in \%).

different micro-environments to the daily average exposure was highly dependent on the ECC.

For the components that presented higher contributions of indoor sources - $\mathrm{OC}$ and $\mathrm{CO}_{3}^{2-}$-similar daily exposure levels were registered in all ECCs, irrespective of their localization (3.4 and $1.4 \mu \mathrm{g} \mathrm{m}^{-3}$, respectively). The contribution of the bedrooms for those compounds was predominant (57\% for both of them).

$\mathrm{Cr}$ and $\mathrm{Zn}$, the elements with the highest ratio $\mathrm{I} / \mathrm{O}$, presented daily average exposure of 10 and $30 \mathrm{ng} \mathrm{m} \mathrm{m}^{-3}$, respectively. These elements had a similar behaviour: higher contribution of bedrooms from ECC 3 and ECC 4 and greater exposure levels from the livingroom of ECC 2.

In the bedroom of ECC 2 the concentration of Sm and Co was always bellow the detection limit $\left(1.6 \times 10^{-3}\right.$ and
$7.6 \times 10^{-2} \mathrm{ng} \mathrm{\textrm {m } ^ { - 3 }}$, respectively), and for this reason the daily exposure was null.

\subsection{Dose assessment}

\subsubsection{Daily average inhaled dose}

The daily average inhaled dose for each elder $\left(E_{\mathrm{di}}\right)$ was assessed by integrating the time spend in each micro-environment, the concentration of the pollutants for the period of interest, the inhalation rate (IR) and the body weight (BW) according Equation (3):

$E_{\mathrm{di}}=\frac{\frac{\sum_{j=1}^{m}\left(C_{i j} \cdot t_{i j} \cdot I R_{i j}\right)}{\sum_{j=1}^{m} t_{i j}}}{\mathrm{BW}}$ 
The IR's associated with the three different micro-environments - bedroom, living-room and outdoor - were recommended by U.S. EPA (2011) for people with more than 61 years old in three distinct activities - sleep, sedentary and light intensity, respectively. These values were selected to be used as the recommended inhalation rates since they were based on three studies: U.S. EPA (2009), Stifelman (2007) and Brochu et al. (2006). Table 6 presents the inhalation values used in this study. The body weight used in this study was $80 \mathrm{~kg}$, also based on U.S. EPA (2011). Although several studies showed that inhalation rate depends on body weights, energy expenditure rate, oxygenation rates, pollutants concentration in each micro-environment, time activity pattern, etc. (Lazaridis and Colbeck, 2010; Brochu et al., 2014), in this work it was not possible to achieve the specific body weight of each elder' voluntary. The daily average inhaled dose was calculated for $\mathrm{PM}_{10}$, carbonaceous components and trace elements for each individual. Table 7 and Fig. 7 present the absolute and the relative daily average inhaled dose for the studied air pollutants and for each ECCs.

$\mathrm{PM}_{10}$ daily average inhaled dose varied between $20 \times 10^{-3} \mu \mathrm{g} \mathrm{kg}^{-1}$ and $28 \times 10^{-3} \mu \mathrm{g} \mathrm{kg}^{-1}$. OC, EC and $\mathrm{CO}_{3}^{2-}$ presented average inhaled doses of $6.0 \times 10^{-3}, 1.6 \times 10^{-3}$ and $2.5 \times 10^{-3} \mu \mathrm{g} \mathrm{kg}^{-1}$, respectively. As it was observed in the exposure levels, higher inhaled doses were registered in ECC 4 for the elements As, Fe, K, Sb, Sc and Sm $\left(1.0 \times 10^{-3}, 250 \times 10^{-3}, 290 \times 10^{-3}\right.$, $1.7 \times 10^{-3}, 0.025 \times 10^{-3}$ and $0.020 \times 10^{-3} \mathrm{ng} \mathrm{kg}^{-1}$, respectively).

The contribution of each micro-environment for the dose (Fig. 7) presented a similar behaviour as the contribution for the exposure and was highly depended on the pollutant and on the ECC.

As far as we know, this work generated the first data on particles components inhaled dose for indoor residential and service buildings. Therefore, it is not possible to compare the inhaled doses measured in this study with results obtained for other indoor environments and populations.

This work showed that the assessment of the integrated exposure to PM components was determinant to accomplish the dose inhaled by elders living in ECCs. In order to compare the personal particle dose with a threshold, an accurate dose evaluation (approaching as much as possible the actual exposure) should to be carried out. This is a crucial aspect, which can only be solved through the assessment of a daily integrated exposure that is able to measure particle concentrations received by people in every micro-environment they visit during a typical day, and by estimating the corresponding doses.

\section{Limitations}

The present work studied the institutionalized elderly exposure and dose to particle components. A couple of limitations were identified during the execution of this work:

Table 6

Inhalation rates used in this study. Based on U.S. EPA (2011).

\begin{tabular}{lll}
\hline Activity & Age group & Inhalation rate $\left(\mathrm{m}^{3} \mathrm{~min}^{-1}\right)$ \\
\hline Sleep & 61 to $<71$ & $5.2 \mathrm{E}-03$ \\
& 71 to $<81$ & $5.3 \mathrm{E}-03$ \\
& $\geq 81$ & $5.2 \mathrm{E}-03$ \\
& Mean & $5.2 \mathrm{E}-03$ \\
Sedentary passive & 61 to $<71$ & $4.9 \mathrm{E}-03$ \\
& 71 to $<81$ & $5.0 \mathrm{E}-03$ \\
& $\geq 81$ & $4.9 \mathrm{E}-03$ \\
Light intensity & Mean & $4.9 \mathrm{E}-03$ \\
& 61 to $<71$ & $1.2 \mathrm{E}-03$ \\
& 71 to $<81$ & $1.2 \mathrm{E}-03$ \\
& $\geq 81$ & $1.2 \mathrm{E}-03$ \\
& Mean & $1.2 \mathrm{E}-03$ \\
\hline
\end{tabular}

a) The first limitation was related to the lack of information about the topic. Despite the importance of healthy air in Elderly Care Centers, IAQ studies have been focused mainly on schools (e.g. Canha et al., 2014a, 2013, 2012a; Pegas et al., 2011a,b; Canha et al., 2011, 2010; Pegas et al., 2010); homes (e.g. Osman et al., 2007), offices (e.g. Bluyssen et al., 1996) and other indoor micro-environments (e.g. Ramos et al., 2014; Viegas et al., 2014). Some of these studies have shown evidence that indoor air pollution increases the risk of respiratory and atopic diseases, but information on health effects of such pollutants in the elderly is scarce.

b) The second limitation was associated with the difficulty to get the support from elderly people. Some elders no longer have their best faculties, being very challenging to: 1) speak with them; 2) understand their concerns; 3 ) explain to them why a group of unfamiliar people were inside their bedrooms; or 4) clarify that the sampling equipments were not dangerous. This is the reason why the authors only studied 4 ECCs and instead of the 10 ECCs that were selected in a previously study (AlmeidaSilva et al., 2014a).

c) Finally, the last limitation was associated with the impossibility to perform measurements near their breathing zone, which is the best approach to calculate the human exposure to air pollutants. Nevertheless, the authors believe that nonsignificant biases were involved in this procedure, since the majority of institutionalized elders do not approached to indoor emissions sources. Truly, they do not cook, do not clean and rarely do something different than stay in the bedroom or living-room.

\section{Conclusions}

In this work, activity pattern data were combined with microenvironmental data on $\mathrm{PM}_{10}$ concentration, using an indirect approach, in order to evaluate the exposure and the inhaled dose of $\mathrm{PM}_{10}$ components (carbonaceous components and trace elements) experienced by elders living in ECCs.

Four ECCs and 193 elders were chosen to undertake the experimental analysis. Time activity pattern data indicated that elders spent the majority of their time in living-rooms and bedrooms and a few percentage spent some time outdoors. Therefore, $\mathrm{PM}_{10}$ was collected in these three micro-environments and their chemical composition was determined. In this work daily exposure and inhaled dose values were reported by the first time for institutionalized elders, highlighting the importance of the time activity patterns and indoor air quality in different microenvironments for the estimation of these parameters. $\mathrm{PM}_{10}$ daily average exposure varied between $11 \mu \mathrm{g} \mathrm{m}^{-3}$ and $16 \mu \mathrm{g} \mathrm{m}^{-3}$ and the daily inhaled dose varied between $20 \times 10^{-3} \mu \mathrm{g} \mathrm{kg}^{-1}$ and $28 \times 10^{-3} \mu \mathrm{g} \mathrm{kg}^{-1}$. Given the high proportion of the day that elders spend indoors, indoor air quality was closely linked to personal exposure. The contribution of each indoor microenvironment for the inhaled dose depended a lot on the particle components and on their respective sources.

Results showed that besides living in the same area, the exposure and the inhaled dose of the studied elders differed significantly. At this point, the authors would like to note that an accurate measurement of integrated exposure is essential to provide an adequate evaluation of the particles dose-response relation. The results of this work show the importance of individual exposure assessment, in order to provide information for the protection of public health, especially for elders who represent one of the most vulnerable groups in society. Integrated exposure studies should be carried out as an essential tool to identify health risks, set and 
Table 7

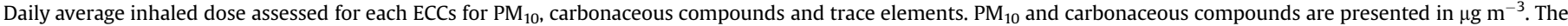
trace elements are present in $\mathrm{ng} \mathrm{\textrm {m } ^ { - 3 }}$. $\mathrm{PM}_{10}$, carbonaceous compounds are presented in $\left(\times 10^{-3}\right) \mu \mathrm{g} \mathrm{kg}{ }^{-1}$ and the trace elements are presented in $\left(\times 10^{-3}\right) \mathrm{ng} \mathrm{kg}^{-1}$.

\begin{tabular}{|c|c|c|c|c|c|c|c|c|c|c|c|c|c|c|c|}
\hline & & $\mathrm{PM}_{10}$ & $\mathrm{OC}$ & EC & $\mathrm{CO}_{3}^{2-}$ & As & $\mathrm{Co}$ & $\mathrm{Cr}$ & $\mathrm{Fe}$ & K & $\mathrm{Na}$ & $\mathrm{Sb}$ & Sc & $\mathrm{Sm}$ & $\mathrm{Zn}$ \\
\hline \multirow[t]{5}{*}{ ECC 1} & $\mathrm{BR}$ & 12.3 & 4.09 & 0.68 & 1.4 & 0.08 & 0.04 & 5.9 & 31.5 & 82.1 & 213 & 0.36 & 0.003 & 0.004 & 10 \\
\hline & LR & 4.19 & 0.93 & 0.26 & 0.38 & 0.01 & 0.02 & 4.5 & 19.9 & 23.9 & 184 & 0.10 & 0.002 & 0.002 & 11 \\
\hline & Out & 2.56 & 0.21 & 0.06 & 0.06 & 0.03 & 0.02 & 2.6 & 22.1 & 22.2 & 152 & 0.11 & 0.002 & 0.002 & 3.5 \\
\hline & Others & 3.74 & 0.83 & 0.23 & 0.34 & 0.01 & 0.01 & 3.9 & 17.8 & 21.3 & 164 & 0.09 & 0.002 & 0.001 & 10 \\
\hline & Total & 22.8 & 6.06 & 1.2 & 2.2 & 0.13 & 0.09 & 16.9 & 91 & 150 & 713 & 0.66 & 0.009 & 0.009 & 35 \\
\hline \multirow[t]{5}{*}{ ECC 2} & $\mathrm{BR}$ & 7.71 & 2.66 & 0.66 & 1.6 & 0.09 & 0.00 & 4.1 & 24.5 & 68.3 & 194 & 0.36 & 0.001 & 0.000 & 11 \\
\hline & LR & 5.55 & 1.23 & 0.49 & 0.49 & 0.09 & 0.04 & 4.7 & 81.2 & 64.7 & 102 & 0.46 & 0.007 & 0.004 & 15 \\
\hline & Out & 0.92 & 0.09 & 0.05 & 0.07 & 0.01 & 0.01 & 0.39 & 10.1 & 6.70 & 41.8 & 0.07 & 0.001 & 0.001 & 1.2 \\
\hline & Others & 3.89 & 0.86 & 0.35 & 0.35 & 0.06 & 0.03 & 3.3 & 56.9 & 45.4 & 71.9 & 0.32 & 0.005 & 0.003 & 11 \\
\hline & Total & 18.1 & 4.84 & 1.6 & 2.5 & 0.25 & 0.08 & 12.5 & 173 & 185 & 410 & 1.2 & 0.014 & 0.008 & 38 \\
\hline \multirow[t]{5}{*}{ ECC 3} & $\mathrm{BR}$ & 10.8 & 4.03 & 0.77 & 1.4 & 0.14 & 0.09 & 8.0 & 48.4 & 73.8 & 128 & 0.38 & 0.006 & 0.003 & 40 \\
\hline & LR & 4.90 & 1.18 & 0.51 & 0.44 & 0.08 & 0.03 & 2.9 & 88.5 & 40.5 & 84.7 & 0.69 & 0.003 & 0.002 & 11 \\
\hline & Out & 0.00 & 0.00 & 0.00 & 0.00 & 0.00 & 0.00 & 0.0 & 0.00 & 0.00 & 0.00 & 0.00 & 0.000 & 0.000 & 0.0 \\
\hline & Others & 1.99 & 0.48 & 0.21 & 0.18 & 0.03 & 0.01 & 1.2 & 35.9 & 16.4 & 34.4 & 0.28 & 0.001 & 0.001 & 4.5 \\
\hline & Total & 17.7 & 5.69 & 1.5 & 2.0 & 0.25 & 0.13 & 12.1 & 173 & 131 & 247 & 1.4 & 0.010 & 0.006 & 56 \\
\hline \multirow[t]{5}{*}{ ECC 4} & BR & 12.4 & 1.72 & 0.69 & 0.76 & 0.61 & 0.06 & 15.9 & 78.5 & 152 & 170 & 0.80 & 0.004 & 0.003 & 39 \\
\hline & LR & 7.11 & 1.69 & 0.44 & 0.86 & 0.17 & 0.04 & 3.8 & 82.9 & 60.8 & 149 & 0.39 & 0.011 & 0.010 & 11 \\
\hline & Out & 0.79 & 0.08 & 0.033 & 0.068 & 0.05 & 0.01 & 0.36 & 13.4 & 70.4 & 81.0 & 0.08 & 0.001 & 0.001 & 1.3 \\
\hline & Others & 4.77 & 1.13 & 0.29 & 0.57 & 0.11 & 0.03 & 2.5 & 55.6 & 40.7 & 99.7 & 0.26 & 0.007 & 0.010 & 7.6 \\
\hline & Total & 25.0 & 4.62 & 1.5 & 2.3 & 0.94 & 0.14 & 22.6 & 230 & 324 & 500 & 1.5 & 0.023 & 0.024 & 60 \\
\hline$E_{\mathrm{di}}$ & & 21 & 5.3 & 1.5 & 2.3 & 0.4 & 0.11 & 16.0 & 170 & 200 & 470 & 1.2 & 0.014 & 0.012 & 47 \\
\hline
\end{tabular}

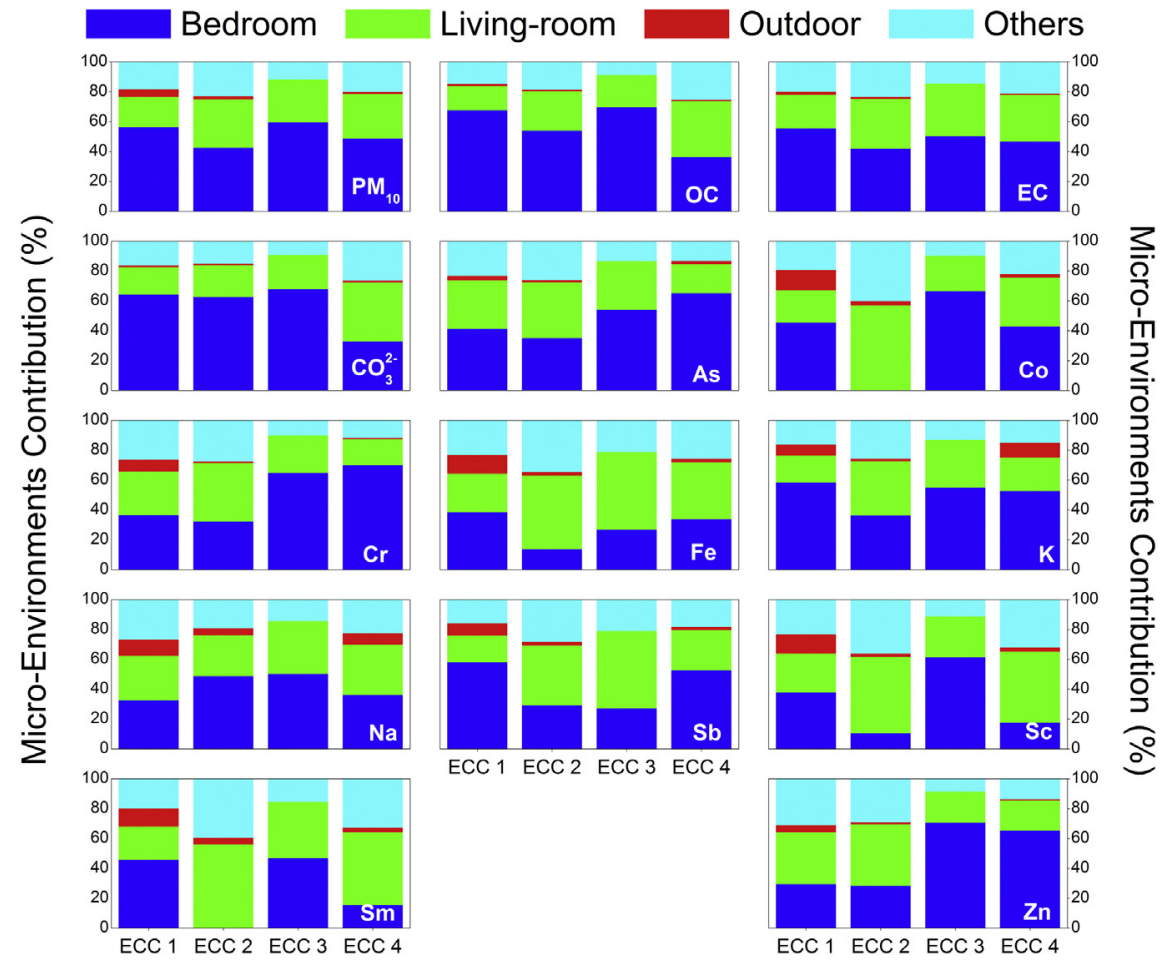

Fig. 7. Contribution of micro-environments to elderly daily dose (values in \%).

review air quality standards and evaluate effective policy interventions.

\section{Acknowledgements}

The study would not be possible without the assistance of Câmara Municipal de Loures, by dr. Luzia Sousa and dr. Beatriz Reis. The comprehensive collaboration of elders supporters and ECCs' owners were crucial for the success of this work. We also gratefully acknowledge Fundação para a Ciência e Tecnologia (FCT) for funding M. Almeida-Silva PhD fellowship (SFRH/BD/69700/2010).

\section{References}

Almeida, S.M., Freitas, M.C., Pio, C.A., 2008. Neutron activation analysis for identification of African Mineral dust transport. J. Radioanal. Nucl. Chem. 276 (1) $161-165$.

Almeida, S.M., Freitas, M.C., Repolho, C., Dionísio, I., Dung, H.M., Pio, C.A., Alves, C. Caseiro, A., Pacheco, A.M.G., 2009a. Evaluating children exposure to air pollutants for an epidemiological study. J. Radioanal. Nucl. Chem. 280, 405-409. 
Almeida, S.M., Freitas, M.C., Repolho, C., Dionísio, I., Dung, H.M., Caseiro, A., Alves, C., Pio, C.A., Pacheco, A.M.G., 2009b. Characterizing air particulate matter composition and sources in Lisbon, Portugal. J. Radioanal. Nucl. Chem. 281, 215-218.

Almeida, S.M., Canha, N., Silva, A., Freitas, M.C., Pegas, P., Alves, C., Evtyugina, M.G., Pio, C.A., 2011. Children exposure to air particulate matter in indoor of Lisbon primary schools. Atmos. Environ. 45, 7594-7599.

Almeida, S.M., Freitas, M.C., Reis, M., Pinheiro, T., Felix, P.M., Pio, C.A., 2013a. Fifteen years of nuclear techniques application to suspended particulate matter studies. J. Radioanal. Nucl. Chem. 297, 347-356.

Almeida, S.M., Silva, A.I., Freitas, M.C., Dung, H.M., Caseiro, A., Pio, C.A., 2013b. Impact of maritime air mass trajectories on the Western European Coast urban aerosol. J. Toxicol. Environ. Health A 76 (4-5), 252-262.

Almeida, S.M., Silva, A.V., Sarmento, S., 2014a. Effects of exposure to particles and ozone on hospital admissions for cardiorespiratory diseases in Setúbal, Portugal. J. Toxicol. Environ. Health A Curr. Issues 77 (14-16), 837-848.

Almeida, S.M., Almeida-Silva, M., Galinha, C., Ramos, C.A., Lage, J., Canha, N., Silva, A.V., Bode, P., 2014b. Assessment of the Portuguese $k_{0}$-INAA laboratory performance by evaluating internal quality control data. J. Radioanal. Nucl Chem. 300, 581-587.

Almeida-Silva, M., Canha, N., Freitas, M.C., Dung, H.M., Dionísio, I., 2011. Air pollution at an urban traffic tunnel in Lisbon, Portugal: an INAA study. Appl. Radiat. Isot. 69 (11), 1586-1591.

Almeida-Silva, M., Almeida, S.M., Freitas, M.C., Pio, C.A., Nunes, T., Cardoso, J., 2013. Impact of Sahara dust transport on Cape Verde atmospheric element particles. J. Toxicol. Environ. Health A Curr. Issues 76 (4-5), 240-251.

Almeida-Silva, M., Wolterbeek, H.T., Almeida, S.M., 2014a. Elderly exposure to indoor air pollutants. Atmos. Environ. 85, 54-63.

Almeida-Silva, M., Almeida, S.M., Gomes, J.F., Albuquerque, P.C., Wolterbeek, H.T. 2014b. Determination of airborne nanoparticles in elderly care centers. J. Toxicol. Environ. Health A Curr. Issues 77 (14-16), 867-878.

Almeida-Silva, M., Almeida, S.M., Wolterbeek, H.T., 2014c. Multi-elemental characterization of indoor aerosols in elderly care centers. J. Radioanal. Nucl. Chem. 300, 679-684.

Alves, C.A., Vicente, A., Monteiro, C., Gonçalves, C., Evtyugina, M., Pio, C., 2011. Emission of trace gases and organic components in smoke particles from a wildfire in a mixed-evergreen forest in Portugal. Sci. Total Environ. 409 (8), $1466-1475$.

Alves, C., Urban, R.C., Pegas, P.N., Nunes, T., 2014. Indoor/outdoor relationships between $\mathrm{PM}_{10}$ and associated organic compounds in a primary school. Aeroso Air Qual. Res. 14, 86-98.

Andersen, Z.J., Wahlin, P., Raaschou-Nielsen, O., Ketzel, M., Scheike, T., Loft, S., 2008 Size distribution and total number concentration of ultrafine and accumulation mode particles and hospital admissions in children and the elderly in Copenhagen, Denmark. Occup. Environ. Med. 65, 458-466.

Aoki, T., Tanabe, S., 2007. Generation of sub-micron particles and secondary pollutants from building materials by ozone reaction. Atmos. Environ. 41, 3139-3150.

Avigo Jr., Devanir, Godoi, A.F.L., Janissek, P.R., Makarovska, Y., Krata, A., PotgieterVermaak, S., Alfoldy, B., Van Grieken, R., Godoi, R.H.M., 2008. Anal. Bioanal. Chem. 391, 1459-1468.

Bluyssen, P.M., Fernandes, E.D., Groes, L., Clausen, G., Fanger, P.O., Valbjorn, O. Bernhard, C.A., Roulet, C.A., 1996. European indoor air quality audit project in 56 office buildings. Indoor Air Int. J. Indoor Air Qual. Clim. 6, 221-238.

Brochu, P. Ducré-Robitaille, J.F., Brodeur, J., 2006. Physiological daily inhalation rates for free-living individuals aged 1 month to 96 years, using data from doubly labeled water measurements: a proposal for air quality criteria, standard calculations and health risk assessment. Hum. Ecol. Risk Assess. 12, 675-701.

Brochu, P., Bouchard, M., Haddad, S., 2014. Physiological daily inhalation rates for health risk assessment in overweight/obese children, adults, and elderly. Risk Anal. 34 (3), 567-582.

Canha, N., Freitas, M.C., Almeida, S.M., Almeida, M., Ribeiro, M., Galinha, C. Wolterbeek, H.Th, 2010. Indoor school environment: easy and low cost to assess inorganic pollutants. J. Radioanal. Nucl. Chem. 286 (2), 495-500.

Canha, N., Almeida, M., Freitas, M.C., Almeida, S.M., 2011. Seasonal variation of total particulate matter and children respiratory diseases at Lisbon basic schools using passive methods. Procedia Environ. Sci. 4, 170-183.

Canha, N., Almeida-Silva, M., Freitas, M.C., Almeida, S.M., 2012a. Lichens as biomonitors at indoor environments of primary schools. J. Radioanal. Nucl. Chem. 291 (1), 123-128.

Canha, N., Martinho, M., Almeida-Silva, M., Freitas, M.C., Almeida, S.M., Pegas, P., Alves, C., Pio, C., Trancoso, M., Sousa, R., Mouro, F., Contreiras, T., 2012b. Indoor air quality in primary schools. Int. J. Environ. Pollut. 50, 396-410 (1/2/3/4).

Canha, N., Freitas, M.C., Almeida-Silva, M., Almeida, S.M., Dung, H.M., Dionísio, L. Cardoso, J., Pio, C.A., Caseiro, A., Verburg, T.G. Wolterbeek, H.Th, 2012c. Burn wood influence on outdoor air quality in a small village: Foros de Arrão, Portugal. J. Radioanal. Nucl. Chem. 291, 83-88.

Canha, N., Almeida, S.M., Freitas, M.C., Taubel, M., Hanninen, O., 2013. Winte ventilation rates at primary schools: comparison between Portugal and Finland. J. Toxicol. Environ. Health A 76, 400-408.

Canha, N., Almeida, S.M., Freitas, M.C., Trancoso, M., Sousa, A., Mouro, F. Wolterbeek, H.T., 2014a. Particulate matter in indoor environments of urban and rural primary schools, by a passive sampling methodology. Atmos. Environ. $83,21-34$.
Canha, N., Almeida, S.M., Freitas, M.C., Wolterbeek, H.T., 2014b. Indoor and outdoor biomonitoring using Lichens at urban and rural primary schools. J. Toxicol. Environ. Health A 77 (14-16), 900-915.

Carvalho, A., Pio, C., Santos, C., Alves, C., 2006. Particulate carbon in the atmosphere of a Finnish forest and a German anthropogenically influenced grassland. Atmos. Res. 80, 133-150.

Chithra, V.S., Nagendra, S., 2013. Chemical and morphological characteristics of indoor and outdoor particulate matter in an urban environment. Atmos. Environ. $77,579-587$.

Chow, J.C., Watson, J.G., Lu, Z., Lowenthal, D.H., Frazier, C.A., Solomon, P.A., Thuillier, R.H., Magliano, K., 1996. Descriptive analysis of $\mathrm{PM}_{2.5}$ and $\mathrm{PM}_{10}$ at regionally representative locations during SJVAQS/AUSPEX. Atmos. Environ. 30, 2079-2112.

De Corte, F., 1987. The $k_{0}$-standardization Method - a Move to the Optimization of Neutron Activation Analysis (Agregé thesis). Gent University, Belgium.

Dung, H.M., Freitas, M.C., Blaauw, M., Almeida, S.M., Dionisio, I., Canha, N.H., 2010. Quality control and performance evaluation of $k_{0}$-based neutron activation analysis and the Portuguese research reactor. Nucl. Instrum. Methods Phys. Res. A 622, 392-398.

Eurostat, 2003. DAI-EPT Results Analysis. Available at: 24Jan14 in: http://en.eustat es/elementos/ele0003200/ti_2003_Time_Budget_Survey_Results_analysis/ inf0003219_i.pdf.

Eurostat, 2006. Christel Aliaga, How is the Time of the Women and Men Distributed in Europe?. Available at: 24Jan14 in: http://epp.eurostat.ec.europa.eu/cache/ ITY_OFFPUB/KS-NK-06-004/EN/KS-NK-06-004-EN.PDF.

Fisher, K., Robinson, J., 2011. Daily life in 23 countries. Soc. Indic. Res. 101, 295-304.

Freitas, M.C., Almeida, S.M., Pacheco, A.M.G., Dionísio, I., Repolho, C., Caseiro, A., Pio, C.A., Alves, C., 2009a. Characterisation of the seasonal exposure to air pollutants for a respiratory epidemiological study. J. Radioanal. Nucl. Chem. 281 (2), 219-223.

Freitas, M.C., Dionísio, I., Beasley, D.G., Almeida, S.M., Dung, H.M., Repolho, C., Pacheco, A.M.G., Caseiro, A., Pio, C.A., Alves, C., 2009b. Association between monthly-reported rhinitis by children from basic schools and monthlyaveraged air pollutants, at Lisbon (Portugal). J. Radioanal. Nucl. Chem. 282 (1), 15-20.

Han, M., Kim, K.Y., Hong, S.C., 2011. Assessment of the charged aerosol value in copy centers. Ind. Health 49, 107-115.

Joshi, S.K., Dhal, A., Kristensen, T., Roldin, P., 2010. Biomass combustion and potential health effects in the developing countries. Kathmandu Univ. Med. J. 8, $276-280$.

Klepeis, N.E., Nelson, W.C., Ott, W.R., Robinson, J.P. Tsang, A.M., Switzer, P., Behar, J.V., Hern, S.C., Engelmann, W.H., 2001. The national human activity patter survey (NHAPS): a resource for assessing exposure to environmental pollutants. J. Expo. Anal. Environ. Epidemiol. 11, 231-252.

Lazaridis, M., Colbeck, I., 2010. Human Exposure to Pollutants via Dermal Absorption and Inhalation. Springer, New York. ISBN: 978-90-481-8662-4.

Meng, Q.Y., Turpin, B.J., Korn, L., Weisel, C.P., Morandi, M., Colome, S., Zhang, J.J., Stock, T. Spektor, D. Winer, A, Zhang, L., Lee, J.H., Giovanetti, R. Cui, W. Kwon, J., Alimokhtari, S., Shendell, D., Jones, J., Farrar, C., Maberti, S., 2005. Influence of ambient (outdoor) sources on residential indoor and personal $\mathrm{PM}_{2.5}$ concentrations: analyses of RIOPA data. J. Expo. Anal. Environ. Epidemiol. 15, $17-28$.

Morawska, L., Afshari, A., Bae, G.N., Buonanno, G., Chao, C.Y.H., Haninnen, O., Hoftmann, W., Isaxon, C., Jayaratne, E.R., Pasanen, P., Salthammer, T., Waring, M., Wierzbicka, 2013. Indoor aerosols: from personal exposure to risk assessment. Indoor Air 23, 462-487.

Nasir, Z.A., Colbeck, I., 2013. Particulate pollution in different housing types in a UK suburban location. Sci. Total Environ. 445-446, 165-176.

Osman, L.M., Douglas, J.G., Garden, C., Reglitz, K., Lyon, J., Gordon, S., Ayres, J.G., 2007. Indoor air quality in homes of patients with chronic obstructive pulmonary disease. Am. J. Respir. Crit. Care Med. 176, 465-472.

Pegas, P.N., Evtyugina, M.G., Alves, C.A., Nunes, T., Cerqueira, M., Franchi, M., Pio, C., Almeida, S.M., Freitas, M.C., 2010. Outdoor/indoor air quality in primary schools in Lisbon: a preliminary study. Quim. Nova 33, 1145-1149.

Pegas, P.N., Alves, C.A., Evtyugina, M.G., Nunes, T., Cerqueira, M., Franchi, M. Pio, C.A., Almeida, S.M., Cabo Verde, S., Freitas, M.C., 2011a. Seasonal evaluation of outdoor/indoor air quality in primary schools in Lisbon. J. Environ. Monit. 13, $657-667$.

Pegas, P.N., Alves, C.A., Evtyugina, M.G., Nunes, T., Cerqueira, M., Franchi, M. Pio, C.A., Almeida, S.M., Freitas, M.C., 2011b. Indoor air quality in elementary schools of Lisbon in Spring. Environ. Geochem. Health 33, 455-468.

Pope, C.A., Burnett, R.T., Thun, M.J., Calle, E.E., Krewski, D., Ito, K., et al., 2002. Lung cancer, cardiopulmonary mortality, and long-term exposure to fine particulate air pollution. J. Am. Med. Assoc. 287, 1132-1141.

Pope, C.A., Burnett, R.T., Turner, M.C., Cohen, A., Krewski, D., Jerret, M., Gapstur, S.M., Thun, M.J., 2011. Lung cancer and cardiovascular disease mortality associated with ambient air pollution and cigarette smoke: shape of the exposure-response relationships. Environ. Health Perspect. 119 (11), 1616-1621.

Public Health Act, 1875. 38\&39 Vict, Ch. 55.

Ramos, C.A., Almeida, S.M., Wolterbeek, H.T., 2014. Exposure to indoor air pollutants during physical activity in fitness centers. Build. Environ. 82, 349-360.

Reynolds, S.J., Black, D.W., Borin, S.S., Breuer, G., Burmeister, L.F., Fuortes, L.J., et al. 2001. Indoor environmental quality in six commercial office buildings in the Midwest United States. Appl. Occup. Environ. Hyg. 16 (11), 1065-1077. 
Saksena, S., Prasad, R.K., Shankar, V.R., 2003. Daily Exposure to air Pollutants in Indoor, Outdoor and in-vehicle Micro-environments: a Pilot Study in Delhi. In: Environ. Change Vulnerabil. Govern. Ser., vol. 57.

Sarmento, S.M., Verburg, T.G., Almeida, S.M., Freitas, M.C., Wolterbeek, H.T., 2011. Robustness of different regression modelling strategies in epidemiology: a time-series analysis of hospital admissions and air pollutants in Lisbon (1999-2004). Environmetrics 22 (1), 86-97.

Simone, M., Jaakkola, M.S., Carrozzi, L., Baldacci, S., Di Pede, F., Viegi, G., 2003. Indoor air pollution and respiratory health in the elderly. Eur. Respir. J. 21 (40), 15-20.

Slexakova, K., Alvim-Ferraz, M.A., Pereira, M.C., 2012. Elemental characterization of indoor breathable particles at a Portuguese urban hospital. J. Toxicol. Environ. Health A Curr. Issues 75 (13-15), 909-919.

Stifelman, M., 2007. Using doubly-labeled water measurements of human energy expenditure to estimate inhalation rates. Sci. Total Environ. 373, 585-590.

Suh, H.H., Zanobetti, A., Schwartz, J., Coull, B.A., 2011. Chemical properties of air pollutants and cause-specific hospital admissions among the elderly in Atlanta, Georgia. Environ. Health Perspect. 119 (10), 1421-1428.

United States Environmental Protection Agency, 2009. Metabolically Derived Human Ventilation Rates: a Revised Approach Based upon Oxygen Consumption Rates (Final Report). Washington, DC EPA/600/R-06/129F.
United States Environmental Protection Agency, 2011. Exposure Factors Handbook: 2011 Edition. Office of Research and Development, Washington, DC, p. 20460.

Valuntaite, V., Girgždiené, R., 2008. Variation of ozone and aerosol particle numerical concentrations on the working premises under different microclimatic parameters. J. Environ. Eng. Landsc. Manag. 16 (3), 135-142.

Viegas, C., Almeida-Silva, M. Gomes, A.Q, Wolterbeek, H.T, Almeida, S.M., 2014 Fungal contamination assessment in Portuguese elderly care Center. J. Toxicol. Environ. Health A Curr. Issues 77 (1-3), 14-23.

World Health Organization, 2010. Guidelines for Indoor air Quality e Selected Pollutants. WHO Regional Office for Europe, Copenhagen.

Zanobetti, A., Franklin, M., Koutrakis, P., Schwartz, J., 2009. Fine particulate air pollution and its components in association with cause-specific emergency admissions. Environ. Health 8, 58.

Zechmeister, H.G., Hohenwallner, D., Riss, A., Hanus-Illnar, A., 2005. Environ. Pollut 138, 238-249.

Zhao, Y., Wang, S., Chen, G., Wang, F., Aunan, K., Hao, J., 2009. Microenvironmenta time-activity patterns in Chongqing, China. Front. Environ. Sci. Eng. China 3 (2), 200-209.

Zwozdziak, A., Sówka, I., Krupinska, B., Zwozdziaka, J., Nych, A., 2013. Infiltration or indoor sources as determinants of the elemental composition of particulate matter inside a school in Wrocław, Poland? Build. Environ. 66, 173-180. 